\title{
Cortés contra el demonio: alteridad en una obra teatral novohispana del siglo XVII
}

\section{Cortés vs. the Devil: Otherness in a Mexican Colonial 17th Century Play in the New Spain}

Víctor Grovas HajJ [victorlibrian@gmail.com] Universidad Autónoma de Querétaro, México

\section{RESUMEN}

El propósito de este artículo, es problematizar, desde la teoría de la alteridad, cómo el demonio funciona como una distorsión del imaginario prehispánico en el teatro del periodo novohispano y cómo el indígena y su mundo es resignificado en uno de los primeros textos teatrales del periodo colonial en la Nueva España, el Coloquio de los 4 reyes de Tlaxcala. Se discuten antecedentes de otras obras que presentaron al extranjero o temas de alteridad hechas por autores españoles emigrados a la Nueva España, pero se da mayor atención a la figura de Cortés como personaje dramático contra el "demonio" Hongol en la obra teatral de Cristóbal Gutiérrez de Luna.

\section{Palabras Clave}

Historia del Teatro Mexicano; alteridad en la literatura; teatro del periodo virreinal mexicano

\begin{abstract}
The purpose of this article is to discuss, with otherness as an interpretative canvas, how the image of the demon works as a distortion of cultural elements of Prehispanic imaginary in the colonial theatre in Mexico. We also explore how the indigenous world is re-signified in Colloquium of the four kings of Tlaxca$l a$, one of the first theatrical texts of the this period in the New Spain. As a background, this essay introduces some other plays made by Spaniards who immigrated to the New Spain, but the focus is given to the conflict between Cortés as a dramatic character and the "demon" in Cristóbal Gutiérrez de Luna’s play.
\end{abstract}

\section{KEYWORDS}

Mexican theater history; otherness in literature; colonial theater in Mexico

RECIBIDO 2018-03-20; ACEPTADO 2018-06-05 
El interés de nuestra reflexión en este artículo es explorar cómo españoles e indígenas, por medio del elemento sincrético de expresión que fue el teatro en el periodo colonial muestran un proceso dialéctico de alteridad-identidad en el intento de significar a otro en una visión del mundo nueva para ambos entes que interactúan en una comunicación que usa como puente al texto literario. La necesidad de representar un mundo nuevo al Otro, lleva a los misioneros a valerse del medio teatral, gestual, como un elemento de comunicación mientras se superaba la barrera del lenguaje. El teatro de Evangelización fue un elemento favorable al proceso de intercambio de elementos culturales. Devino en un sincretismo, pues ninguna cultura podía suplantar a otra a pesar del esfuerzo de los misioneros de suprimir la divulgación de la tradición indígena (Sten 1974: 48-75). Como apunta Horcasitas, en la Europa medieval, y en la España que conocían los conquistadores de México, no era ajena a la mentalidad contemporánea la participación, integración e identificación del pueblo en los grandes espectáculos dramáticos (Horcasitas 2004: 86). Es por esto que los bailes anteriormente descritos se conservaron, bajo el disfraz de las danzas de moros y cristianos. Un baile sobre una guerra del Otro, trasladaba, al menos en el Gesto, la confrontación reciente en el mundo disimulado de la ritualidad indígena en el siglo XVI. Un ejemplo de ello, nos lo da Motolinia, al referirse a la representación de la "Conquista de Jerusalem" con motivo de las fiestas del Corpus en Tlaxcala en 1538, en la que los indígenas hacen de Cortés un cruzado que vence al "Tlatoani ${ }^{1}$ de Jerusalem" (Motolinia 1985: 188). Nos dice María y Campos (1959: 33-34) que en 1566 se representó “en la casa de Alonso de Avila, hijo del capitán conquistador, La primera entrada de Cortés a Tenochtitlán, con motivo del nacimiento de los mellizos de don Martín Cortés”. Ambos eran personajes protagonistas de la primera conjura contra los "gachupines". El espíritu criollo y el primer intento de independencia de la Corona española se asociaban al teatro desde los primeros años de la Colonia.

Auspiciadas por la primera generación nacida en la Nueva España, y para celebrar el centenario de la Evangelización y la Conquista de México se convoca a justas poéticas y se hacen obras teatrales con este tema. Luego de que Balbuena se consagra con su poema épico Grandeza Mexicana (1604), que ya resalta la importancia de la actividad teatral en la naciente metrópoli, el Bachiller Arias de Villalobos ocupa el lugar de Balbuena. González de Eslava, en su Coloquio VII escrito antes de 1600, había introducido ya la primera alusión al extranjero-lejano, cuando la esposa de un criollo quiere irse a la China y en el Coloquio X hace la distinción entre el español honrado y el mestizo que es dado al engaño (González 2006: 44). Arias de Villalobos se convierte, como decíamos, en el poeta más celebrado de la Nueva España en ese entonces, pero también en uno de los autores dramáticos más solicitados por el Virrey para las presentaciones teatrales en las postrimerías de la Colonia. Villalobos será el primero en introducir el tema de la Conquista en formas pseudo-dramáticas que aún oscilan entre los cantares de gesta y las representaciones teatrales, que se escenificaban improvisadamente y en los que la recitación era más importante, representadas por dos actores, como en el caso del Ñaque peninsular. Estos son llamados en la Nueva España "diálogos". Dicha forma será muy popular durante la época colonial en México y aún la encontraremos como instrumento de difusión de las ideas de los bandos conservador y liberal en la independencia, ya entrado el siglo XIX. Así tenemos de Arias de Villalobos el "diálogo de Moctezuma y Cortés" que si aún no tiene una forma estrictamente 
teatral, es uno de los primeros textos mexicanos aún existentes que enfrenta al emperador indígena y al conquistador español. En el texto ya encontramos muchos aztequismos, como "Chilmol”, "Macehual”, "Suchicopal”, etc., así como alusiones a costumbres indígenas, entre las que se destaca la referente a los "areitos y mitotes" como son llamadas por los cronistas las representaciones teatrales de los indios.

Pero el primer documento estrictamente teatral que aún se conserva sobre la confrontación de los indígenas y los españoles es el Coloquio de la nueva conversión y bautismo de los cuatro últimos reyes de Tlaxcala, del que nos ocuparemos. Esta obra, luego de apasionada polémica², se ha determinado que pertenece al criollo don Cristobal Gutiérrez de Luna y su fecha más posible es 1619. Como Winston A. Reynolds explica, esta es la primera obra mexicana existente que convierte al conquistador español Hernán Cortés en protagonista. Lo interesante es que Cortés no es el único personaje de la obra proveniente de ultramar sino también el demonio Hongol, que encarna a los dioses prehispánicos y por ello a las creencias prehispánicas, que aún influían en todos los niveles de la sociedad indígena. Esto refleja el extrañamiento de la idiosincracia indígena en el contexto cultural de un criollo de principios del siglo XVII. El nombre del demonio, "Hongol", no proviene de un conocimiento directo de los dioses del panteón indígena de México, Tenochtitlan, o de Tlaxcala, donde se compone la obra sino de una fuente literaria sudamericana (Alonso de Ercilla: La Araucana, 1569-1589) retrabajada por Lope de Vega en El Nuevo mundo descubierto por Cristóbal Colón de donde Gutiérrez de Luna roba algunas quintillas (Reynolds 1969: 179-181)3. En Las hazañas del Marques de Cañete, que escribe Alarcón en colaboración con otros autores, también se evidencia el uso de la fuente de la Araucana. Así, el conocimiento del mundo prehispánico, a cien años de la Conquista era, en algunos casos, algo reelaborado e importado. El Hongol original es el capitán valiente y temible de los araucanos. En la obra de Gutiérrez de Luna, su extrañamiento de lo indígena lo convierte en un ser diabólico. Los nombres de los indios se representan, por contraste, de acuerdo con los nombres históricos en náhuatl. Al personaje extranjero, Cortés, se le designa en el Coloquio como "El Marqués del Valle". Este título nobiliario aparece también constantemente en las crónicas indígenas de la Conquista para resaltar su condición de noble. El título lo liga más a la tierra mexicana, precisamente por su nombramiento como Marqués del Valle de Oaxaca.

En el primer acto hay tristeza por el silencio de Hongol, que parece aludir a una culpa, desde la perspectiva del autor, que necesariamente deben sentir los indígenas por adorarle. Mediante los personajes se hacen referencias múltiples al Sol como deidad adorada. Entre los

2 El manuscrito, escrito junto con una "relación" de Cortés y una biografía del Arzobispo Moya y Contreras, figura capital del siglo XVI en la política novohispana, tuvo entre sus primeros dueños a Sigüenza y Góngora, una de las figuras más importantes de la literatura novohispana en México. Luego de permanecer mucho tiempo en el Colegio Máximo de la Compañía de Jesús y en la Biblioteca de la Real y Pontificia Universidad de México, llegó en el siglo XIX de manos de uno a otro coleccionista a Genaro García, cuya colección privada fue adquirida por la Universidad de Texas. Aunque la obra estaba firmada en 1619 con el nombre de Cristóbal Gutiérrez de Luna el bibliotecario de la Universidad, Castañeda, fue el primero en dudarlo y lo atribuye a Motolinia en 1932 en su artículo "The first american play”.. Clementina Díaz de Ovando en 1941 coincide con Castañeda. Usigli, en México en el Teatro y Angel María Garibay en Historia de la Literatura Náhuatl, tomo II, se ocupan del manuscrito y confirman la autoría de Cristóbal Gutiérrez de Luna. Winston A. Reynolds, en 1969 hace una revisión crítica de los criterios de paternidad atribuidos al texto y considera que la fecha coincide con el centenario del supuesto suceso del bautismo de los reyes, como consta en el Lienzo de Tlaxcala (Reynolds 1969: 172-184).

3 (Reynolds 1969: 179-181) cita las quintillas de El Nuevo Mundo de Lope de Vega y las compara con las del Coloquio. 
anacronismos, comunes en la literatura de la época, como la referencia a Neptuno hecha por los indios, podemos observar una transposición del culto al dios del agua, Tlaloc. Hay referencias a los sacrificios humanos, presentes en los rituales indígenas una centuria atras (Garcidueñas 1976: 189). Gutiérrez de Luna muestra, a pesar de su extrañamiento consciente, que tiene conocimientos de la cultura náhuatl, como también lo hace más tarde Sor Juana Inés de la Cruz. El "desconocimiento" de Gutiérrez de Luna no es otra cosa que un "obligado distanciamiento", por la censura religiosa; para probarlo, revisaremos algunos motivos que se incluyen en la obra y que, comparados con una fuente histórica especializada en la historia indígena en Mexico y Tlaxcala (Motolinia), muestran que el autor criollo no cita nombres falsos por desconocimiento, sino por voluntaria inhibición, en este caso por censura.

Cristóbal Gutiérrez nos habla, ya en el inicio de su Coloquio de los "nahuateyes" asociados a Quetzalcóatl ${ }^{4}$. El texto alude claramente a la leyenda de los 4 soles (Gutierrez 1976: 191). Otro elemento prehispánico, también cercano al mito de Quetzalcóatl, que a su vez explica en la cosmogonía indígena la llegada de los españoles. El suceso de la conversión de los 4 reyes tlaxcaltecas no ha sido tomado de las principales fuentes de los cronistas. Necesariamente se inspira en un documento primario realizado por los indígenas a modo de códice: el Lienzo de Tlaxcala ${ }^{5}$. La asociación que hace Gutiérrez de Luna de los indios con las culebras, también alude a la relación de la culebra con el diablo, muy presente en el discurso de los cronistas. La relación de las culebras y los sueños en el texto se explica también mediante lo expuesto en las crónicas de Motolinia cuyos escritos, parcialmente hechos en Tlaxcala, podrían haber sido una fuente para Gutiérrez de Luna. Este dice que con los hongos alucinógeneos (Teonanacatl) los indios “veían mil visiones, en especial culebras" (Motolinia 1985: 208). La alusión a las flores es igualmente importante en el Coloquio. Motolinia hace una apología de las sorprendentes ofrendas de flores de los indios durante las fiestas del Corpus Christi (36). El texto del Coloquio se refiere a las ofrendas de Copalli a Hongol: "A su divino templo y a su culto/ después de haber quemado mil aromas" (Gutiérrez 1976: 190). Motolinia dice: "ofrecían al demonio mucho papel y copalli” y en varios lugares de los Memoriales explica el uso del "copalli" o copal, como incienso ${ }^{6}$. Esto confirma en el texto que Gutiérrez de Luna las particularidades de los rituales del Otro.

Los sueños premonitorios, que en la pieza anticipan a los monarcas aztecas el establecimiento del cristianismo en México, recuerdan los augurios del regreso de Quetzalcóatl, que atormentan a Moctezuma. Las primeras imágenes que los indios sueñan anticipan su confrontación con

4 El nahuateye, también conocido como nahual, es un elemental o demonio presente en la mitología náhuatl, como lo hemos visto en el mito de Quetzalcóatl. Lo que es interesante observar es que este ser, que tiene un parentesco con las criaturas elementales provenientes del agua en la mitología europea, tiene que ver con la duplicación, por pertenecer al elemento líquido, que refleja lo que ve. En relaciones orales de las costas de Guerrero y Oaxaca en México los habitantes se refieren a las nahualas, que toman la forma del ser querido para perder a sus víctimas en las lagunas de los bosques durante la época de crecidas. Los nahuales pueden ser también, si lo desean, guías. Hemos visto que el nahual de Quetzalcóatl es su doble.

5 No mencionan el hecho en sus crónicas Cortés, Gómara Tapia, Herrera ni Gobernantes. Bernal Díaz lo niega. Lo afirma, como hemos dicho, el Lienzo de Tlaxcala, Motolinia también calla. Por el contrario, el indígena Alva Ixtlixochitl sí lo refiere. Muñoz Camargo y Torquemada también lo hacen posteriormente.

6 El copalli es descrito como "una resina blanca, que se cría en unos árboles en tierra caliente, a los cuales, cruzándolos para que destile esta goma o resina, sale de ello en cantidad sobre unas pencas grandes... todo esto en lugar de incienso" (Motolinia 1985: 18, 35, 41 y 46). Hoy en día el copal se usa mucho en México en las ceremonias de la liturgia cristiana. 
Cortés en su papel de cruzado, preocupado más por la evangelización que por los beneficios materiales de la Conquista ${ }^{7}$. Estas imágenes son tan idealizadas como la caracterización de este personaje. Al introducir a los extranjeros en su pieza, el autor intenta, mediante la descripción de uno de los indígenas de su sueño premonitorio, un imaginativo distanciamiento de la figura del español que el autor conoce bien:

\author{
ZITLALPOPOCATZIN: \\ No fue ilusión o sueño, ni fue sombra \\ sino que por mis ojos vi que estaban, \\ al parecer en una rica alfombra, \\ unos hombres, que apenas divisaban \\ mis turbados ojuelos temerosos... \\ No sé qué siento de lo que miraban, \\ estaban, como dicen, cuidadosos \\ o, por mejor decir, como el que mira \\ dos animales fieros, poderosos, \\ que no se atreve a disparar la vira \\ por no errar el tiro, que le importa \\ no menos que la vida si les tira. \\ ¡Ah que mi fiero ánimo se acorta \\ soñando gente extraña en nuestra tierra! (Gutiérrez 1976: 191)
}

Aquí, el Criollo Gutiérrez de Luna logra una representación designificada del español, de la misma manera con la que su contemporáneo, el español Balbuena, en algunos momentos de su Grandeza Mexicana, omite la descripción de lo mexicano, aunque la tiene a la vista, y se torna ambiguo en los detalles, en beneficio del lucimiento formal. Aquí el español se difumina, es un ser indescriptible, todo mirada, que no es caracterizado más que como el Otro, que observa y es observado -primera condición de la comprehensión del Objeto y primera regla del teatro, que esta asociado a la voz latina Teomain: "lugar desde donde se ve". La alfombra completa esta imagen exótica. Pareciera como si estos seres etéreos, en cuanto a que son criaturas del sueño y a que no están casi caracterizados, pudieran flotar en la rica "alfombra" hasta la indefinición desde la perspectiva del narrador ${ }^{8}$. Para distanciar al español, el autor implícito debe recurrir a una imagen de un extranjero lejano en su reelaboración del personaje. ¿Es acaso el extranjero del medio-oriente, ya introducido en los "bailes" de la Conquista, base de la idea de la "rica alfombra”? El ángel, que se adelanta al demonio en la aparición, también se presenta como un Deus ex machina del autor, y como un representante idealizado del ideario religioso español.

La caracterización del personaje del demonio es más precisa, aunque presupone un esfuerzo imaginativo para representar al mundo cultural prehispánico, del que el autor criollo quiere distanciarse. El dios indígena se convierte en un personaje importante para el desarrollo de la

$7 \quad$ Una caracterización del Conquistador común en el teatro colonial, como aún lo veremos en El apostolado en las Indias y Martirio de un cacique, de Eusebio Vela, en el siglo XVIII.

8 La percepción también indica lejanía, falta de claridad: "unos hombres que apenas divisaban / mis turbados ojuelos temerosos". 
acción?. Hongol es un pseudónimo de los dioses paganos, innombrables por censurados en la sociedad de Gutiérrez de Luna ${ }^{10}$. Las semejanzas entre Hongol y Camaxtli, parecen mostrar que el autor no desconoce totalmente a los dioses que piensa aludir. En el Coloquio, Hongol está representado como un "gran ídolo" en el texto. Motolinia menciona que los indígenas, especialmente en Tlaxcala, adoraban especialmente a un dios regional: Camaxtli, al que el misionero español describe en varias ocasiones como un "ídolo grande", tal como sucede en la obra. Camaxtli es un voraz adicto a los sacrificios humanos, cualidad que comparte con el Hongol del Coloquio (Motolinia 1985: 226).

La descripción de los españoles como "hijos del Sol", también los iguala con la existente en el mito prehispánico. El Sol será el elemento de unión de ambas cosmovisiones en el texto y así, los indígenas se explican que los españoles son poderosos porque tienen el poder del Sol (Gutiérrez, 1985: 195) como les explica el demonio Hongol. Es interesante advertir que Hongol, antes del encuentro con los españoles, sí tiene la posibilidad de describir a los indígenas, con nombres y señales, la región de la que vienen los extranjeros: "Sabed amigos -les dice- que el Sol/ en las partes del (sic.) Europa/ que es en Castilla, creó/ unos hijos con su sombra" (196). Pronto sabremos que Hongol es un desterrado, familiar en la cosmogonía del viejo mundo -el ángel caído Lucifer- cuando dice " ¿No soy quien, parte del cielo trajo a la tierra con sí? (193) [...]. No basta haberme quitado de mi divino lugar?” (197). Hongol expresa explícitamente su queja al emperador de la Conquista, Carlos V, al que llama atrevidamente "gusano", y culpa al poderío español de haberle quitado la "cuarta parte de la tierra" ${ }^{11}$. Finalmente, se muestra con toda claridad, no solo como un Luzbel desterrado del cielo, sino como un desterrado en Europa, extranjero en América: el último retiro de Hongol son las Indias a las que él mismo llama "tierras remotas/ donde por dios me adoraban estos bárbaros idiotas" (Gutiérrez 1985: 213). Esta extranjerización de Hongol se asocia también con el mito de Quetzalcóatl, el dios extranjero que vive un tiempo en América. Camaxtli, el dios regional que parece ilustrar Gutiérrez de Luna en la figura de Lucifer, es además una variante tlaxcalteca del dios Quetzalcóatl (Motolinia 1985: 26 y 42$)$.

La obra de la que Cristóbal de Luna sustrae algunos versos, como hemos dicho, es El Nuevo mundo descubierto por Cristóbal Colón de Lope de Vega. En el Coloquio, Cortés, como el Colón de la obra citada de Lope, sabe que su justificación para descubrir y conquistar es la evangelización (Gutiérrez, 1985: 200). Su rol de conquistador es vedado, e incluso condena a la "antigua y fiera guerra/ que tantos siglos tuvo al hombre atado/ y (me) destierra mi justo pecho y celo enamorado" (202).

Se muestra a Cortés por primera vez en el encuentro de Tecoacingo, lo que coincide con lo dicho por Motolinia y se omiten las guerras primeras de Cortés con los Otomíes que menciona

9 El demonio funcionará como el personaje que otorgará dinamismo al estático desarrollo de la acción dramática en la obra (cf. Reynolds 1969: 177).

10 Sor Juana hará lo mismo en su Loa al auto sacramental del divino Narciso, con la figura de Huitzilopochtli, que llama "el dios de las semillas".

11 (Gutiérrez, 1985: 213). Este conflicto personal entre el demonio y Carlos V se muestra también en Arias de Villalobos, quien imagina en su Mercurio al emperador como Hércules victorioso ante el monstruo hereje. La tradición será continuada por otros autores coloniales, como lo ilustra el caso del jesuita José Lucas Anaya en su Verdadera metamorfosis... donde Lucifer también se queja de la derrota sufrida por Carlos V (Sola 1973: 366-367). 
el misionero dedicado a la revisión de las representaciones teatrales (Motolinia 1985: 16). Así se desvincula aún más a Cortés de su representación como guerrero ${ }^{12}$. Aquí Gutiérrez de Luna ignora la crítica de la versión indígena, de la que está enterado en algunos aspectos, como veremos, e incluso elude la crítica de los cronistas en cuanto a la avidez del conquistador por el Oro, y lo exonera totalmente cuando le hace decir: "A vuestra tierra he llegado/ siendo de un Rey enviado/ no a quitaros vuestro oro/ piedras ni rico tesoro/ sino que a Dios conozcais" (Gutiérrez 1985: 206-207). A Cortés se le identifica con otras actividades no militares. Es el autor de las Cartas de relación con su "estilo pulido" y su "relación novelesca". Esta caracterización lo acerca más al autor. Cortés no es aquí un héroe emblemático, sino un ser humano que se "espanta" de su decisión osada de la quema de naves. Para identificarlo aún más con el público criollo de su tiempo, rinde pleitesía en el texto a México, que lo tiene "tímido y perpléjico" (sic) (212).

Los caballos y cañones de los españoles son consignados en el documento histórico indígena, contra lo que se piensa, con asombro pero con realismo, no como una descripción de algo sobrenatural. En el Coloquio, la descripción de las nuevas armas y cosas que traen los españoles son, como los templos del churrigueresco hispanoamericano, amenizados por la imaginería del Criollo Gutiérrez de Luna, que ya distancia, al ironizar sobre la percepción del Otro: las carrozas parecen a los indios "casas con cordeles" y la armadura es identificada como un "animal poderoso". Estas descripciones son invenciones del autor. No coinciden con las fuentes históricas (196).

Xicoténcatl, figura predominante y pro-española, paradigma en el documento indígena de la alianza española-tlaxcalteca que consigue el triunfo sobre los mexicas, es aquí un personaje destacado entre los otros reyes tlaxcaltecas e incluso es caracterizado, en concordancia con el rey histórico, como un hombre viejo ${ }^{13}$. Esta es otra muestra del conocimiento del autor de fuentes de primera mano. Gutiérrez de Luna conoce también la importancia de los otros 3 reyes que incluye en su Coloquio e incluso proporciona el segundo nombre de Xicoténcatl: Zitlai (Motolinia 1985: 201), lo que no se encuentra en la escrupulosa descripción de Motolinia sobre los reyes tlaxcaltecas ${ }^{14}$. Sin embargo, Gutiérrez de Luna, como más tarde Sor Juana, ante la interminable tarea de todo un siglo de imponer el cristianismo a las arraigadas tradiciones indígenas, comprende la "dificultad" que significa para los indios el cambio de religión. Sólo el deus ex machina de la aparición del ángel -esto es, un milagro- puede resolver esta dificultad técnica para mostrar la transición en los personajes, y esta anagnórisis parece aquí un tanto forzada y apresurada. Los indios, están representados ya como seres "nobles y gallardos" de la misma manera en que serán idealizados por Sor Juana en sus Autos Sacramentales ${ }^{15}$, pues ya

12 (Motolinia 1985: 11). Es interesante mencionar que se llegó a atribuir la obra a Motolinia, conocido por su entusiasmo por los eventos teatrales y su importante contribución al teatro de Evangelización. Gutiérrez de Luna, quien tal vez era un escribano -se conoce poco de él, salvo su origen criollo que él subraya en el folio del título- pudo solamente retocarla y adueñarse de la obra. Reynolds menciona esto y descarta esta hipótesis, cuyo origen podemos entender por la similitud con el texto y las coincidencias con los textos deMotolinia. Aspectos como los que señalamos aquí (la omisión de las guerras Otomies) o el silencio de Motolinia, cronista principal de Tlaxcala, sobre el episodio, agregan elementos a la tesis desarrollada en el texto de Reynolds (1969: 172-184).

13 (Motolinia, 1985: 102). Motolinia además, lo describe como un hombre ciego.

14 Son, de hecho, como documenta Motolinia, los cuatro señores principales de los reinos de Tlaxcala: Tepeticpac, Ocotelolco, Tizatlán y Quiyahuizilan.

15 En su Loa al Auto Sacramental del Divino Narciso. 
pertenecen al "folklor" del que se apropia la nueva generación de criollos. Los indígenas en esta obra se encuentran entre la influencias de dos extranjeros: el cruzado Cortés y el demonio Hongol quien es al mismo tiempo Lucifer, Quetzalcóatl, Camaxtli.

En cuanto al conflicto dramático, el encuentro de los españoles y los indígenas no será aún representado en este texto como una confrontación violenta. Tendremos que esperar a las obras de Vela en el siglo XVIII o de Ramírez en el XIX. La labor conciliadora de los evangelizadores, quienes fomentan la creación de este tipo de teatro, y la pervivencia de las dinastías y los resabios de la influencia local de las clases altas indígenas (un potencial público de este texto) se presentan como las causas de este fenómeno. La opinión de otros cronistas de la evangelización contemporáneos a Gutiérrez de Luna como Acosta, Torquemada y Palafox de Mendoza es que la cultura idólatra de los indígenas está casi exterminada. Motolinia, que como se ha visto, debió ser una fuente de Gutiérrez de Luna, comparte la opinión, que más que a la ingenuidad, el autor obedeció a un esfuerzo propagandístico para mostrar al receptor último de estos textos (las autoridades y opinión pública española) el triunfo de la labor evangelizadora. Nosotros concordamos con esta visión. La figura de Cortés se representa en el texto como una imagen hierática. Esto contrasta con el dinamismo de Hongol en la acción dramática. Cortés dice que los ojos humanos de los cristianos no pueden ver a Hongol (Gutiérrez 1985: 215). El dios sólo puede ser visto por los indígenas. El exorcisado Hongol representa el mundo al que sólo ellos tuvieron acceso: el de la cultura y la religión prehispánicas, que para el siglo XVII se encontraba censurado, pero de ningún modo eliminado.

\section{Referencias bibliográficas}

Berendova, A. T. (2000). La identidad nacional y la conciencia criolla en los autores del Barroco Novohispano. Signos Literarios y Lingüísticos, $V$, 2, 47-64.

Bravo Arriaga, M. D. (2005). Las Loas de los autos de Sor Juana: los signos de la Tolerancia. In S. Lorenzano (Ed.), Aproximaciones a Sor Juana (pp. 51-60). México: Fondo de Cultura Económica.

Cortés, H. (2015). Cartas de Relación de la conquista de América. México: Porrúa.

Detering, S. (1996). Kolumbus, Cortés, Montezuma: die Entdeckung und Eroberung Lateinamerikas als literarische Sujets in der Aufklärung und im 20. Jahrhundert. Weimar: Verlag und Datenbank für Geisteswissenschaften.

Egan, L. (1998). Un ángel caído como abogado del diablo: la "demonología” de Sor Juana. In C. B. López Portillo (Coord.), Sor Juana y su Mundo: Una Mirada Actual. Memorias del Congreso Internacional (pp. 193-99). México: Universidad del Claustro de Sor Juana / UNESCO / Fondo de Cultura Económica.

González, A. (1997). Texto y representación en el Teatro del Siglo de Oro. México: Colegio de México.

González de Eslava, F. (2006). Coloquios espirituales y sacramentales 1-2. México: Porrúa.

Grovas Hajj, V. (2001). El otro en nosotros. México: Fontamara.

Gutiérrez de Luna, C. (1976). Coloquio de la Conversión de los Cuatro Reyes de Tlaxcala. In J. Rojas Garcidueñas et al (Eds.), Tres Piezas Teatrales del Virreinato. México: Universidad Nacional Autónoma de México. 
Hölz, K. (Ed.) (1988). Literarische Vermittlungen: Geschichte und Identität in der mexikanischen Literatur; Akten des Kolloquiums Trier 5. bis 7. Juni 1987. Tübingen: Niemeyer.

Horcasitas, F. (2004). El teatro náhuatl. Épocas novohispana y moderna. México: UNAM.

Kohut, K. (1997). Pensamiento europeo y cultura colonial: textos y estudios coloniales y de la Independencia. Frankfurt am Main: Vervuert-Iberoamericana.

Lafaye, I. (1988). Quetzalcoatl y Guadalupe. México: Fondo de Cultura Económica.

Maria y Campos, A. (1959). Representaciones teatrales en la Nueva España (siglos XVI al XVIII). México: La escena mexicana.

Méndez Plancarte, A. (1944). Poetas Novohispanos (1621-1721). México: UNAM.

Messinger, S. (1991). La malinche in Mexican Literature. Austin: University of Texas.

Motolinia (Fray Toribio de Benavente). (1985). Memoriales e Historia de los indios de la Nueva España. G. Baudot (Ed.). Madrid: Castalia.

Nigro, K. (1987). Rhetoric and history in three Mexican plays. Latin American theatre review, 21, 1, 65-73.

Olavarría y Ferrari, E. (1961-1968). Reseña histórica del teatro en México (5 vols.) México: Porrúa.

Ramos, S. (1997). El perfil del hombre y la cultura en México. México: Espasa-Calpe Mexicana.

Reynolds, W. (1969). El demonio y Lope de Vega en el manuscrito mexicano Coloquio de la Nueva Conversión y Bautismo de los cuatro últimos Reyes de Tlaxcala en la Nueva España. Cuadernos Americanos, CXLIII, 2, marzo-abril, 172-184.

. (1978). Hernán Cortés en la literatura del Siglo de Oro. Madrid: Editora Nacional.

Ripodas Ardanaz, D. (1991). Lo indiano en el teatro menor español de los siglos XVI y XVII. Madrid: BAE 301.

Sola, S. (1973). El diablo y lo diabólico en las letras americanas. (1550-1750). Deusto: Castalia. Publicaciones de la Universidad de Deusto (Filosofía y Letras).

Simon, C. (2002). Patriotismo criollo: la Loa Introductoria a El divino Narciso. Universidad de México, 611, $50-53$.

Sten, M. (1974). Vida y muerte del teatro náhuatl. México: UNAM.

Todorov T. (1994). La conquista: el problema del Otro. México: Siglo XXI.

(1997). Relatos aztecas de la Conquista. México: Grijalbo-CNCA. 
